\title{
Effect of a 12-hour natural drainage technique on decreasing blood loss after total knee arthroplasty: a case-control study
}

This article was published in the following Dove Press journal:

Therapeutics and Clinical Risk Management

\author{
Mingmin Shi' \\ Jinjie Zhang ${ }^{2}$ \\ Yujie Zhang' \\ Shigui Yan' \\ Haobo Wu' \\ 'Department of Orthopaedic Surgery, \\ Second Affiliated Hospital, School \\ of Medicine, Zhejiang University, \\ Hangzhou 310009, People's \\ Republic of China; ${ }^{2}$ Department \\ of Orthopedics, First Affiliated \\ Hospital of Zhejiang Chinese Medical \\ University, Hangzhou 310006, People's \\ Republic of China
}

Background: Different methods of drainage have been used in patients with osteoarthritis after total knee arthroplasty (TKA), but the ideal strategy is controversial. This retrospective case-control study reported a technique of 12-hour natural drainage and aimed to confirm its efficacy and safety in the treatment for blood loss following TKA.

Methods: There were 231 patients divided into three groups who underwent TKA from January 2014 to July 2017: 76 patients underwent 12-hour natural drainage in Group A, 80 patients underwent 4-hour clamping drainage in Group B, and 75 patients underwent continuous drainage in Group C. All perioperative clinical data were reviewed for statistical analysis.

Results: The drainage volume and total blood loss after TKA were significantly lower in Group A than that in the other two groups $(P<0.05)$, and serum level of hemoglobin was significantly higher in Group A than that in the other two groups $(P<0.05)$. The maximum of active motion of the knee was greater in Group $\mathrm{C}$ at 2 days $(P<0.05)$. Significantly more patients in Group $\mathrm{C}$ required blood transfusions $(P<0.05)$. No difference was found in the complication rate among the three groups.

Conclusion: The 12-hour natural drainage is an effective technique for reducing blood loss for patients following TKA. Compared with temporary clamping drainage and continuous negative pressure drainage, 12-hour natural drainage decreases blood loss, reduces post-operative transfusion requirements, and does not increase the risk of complications. Therefore, this technique of 12-hour natural drainage is recommended to be used in patients after TKA.

Keywords: natural drainage technique, blood loss, total knee arthroplasty, case-control study

\section{Background}

Total knee arthroplasty (TKA) is a standardized surgery in the therapy of advanced knee osteoarthritis and rheumatoid arthritis. The aims of TKA are correcting joint abnormality, relieving pain, and restoring joint function. Nowadays, this procedure is considered as one of the most effective treatments in orthopedic practice. ${ }^{1}$

Drainage is routinely used in TKA to prevent wound hematoma, facilitate wound healing, and reduce infection risk. However, anemia is common following TKA, which is caused by local hemorrhage associated with soft tissue damage and osteotomy. ${ }^{2,3}$ To reduce and control the blood loss, various methods have been investigated, including tranexamic acid, ${ }^{4,5}$ fibrin agent, and clamping drainage. ${ }^{6}$ Clinical evidence shows that drainage clamping is an optimal method to decrease the blood loss and other complications following TKA. ${ }^{7,8}$ But controversy still exists regarding whether clamping drainage or continuous drainage (no drainage clamping) is preferable after TKA.
Department of Orthopaedic Surgery, Second Affiliated Hospital, School of Medicine, Zhejiang University, No 88 Jiefang Road, Hangzhou 310009, People's Republic of China

$\mathrm{Tel}+8613958122387$

Fax +86 57I 87783882

Email 2505014@zju.edu.cn 
Theoretically, continuous drainage (no clamping drainage) systems can decrease hematoma formation, which might decrease post-operative pain, relieve swelling, and reduce the risk of infection. ${ }^{9,10}$ However, it was reported that no clamping and negative drainage might increase the volume of blood loss. Although many studies showed no advantage of continuous drainage systems after TKA, ${ }^{11-13}$ it is still one of the routine procedures used by surgeons. It was reported that non-continuous drainage can form a tamponade, which may reduce blood loss, and the recommended clamping duration is 3-6 hours. ${ }^{14-16}$

In the present study, we use a novel technique of 12-hour natural drainage following TKA, which means that drainage is with atmospheric pressure in the first 12 hours after TKA and then changed to be with negative pressure. We also conducted no clamping drainage and 4-hour clamping drainage as two control groups for comparison. This case-control study aims to confirm the effect of temporary natural drainage on blood loss in patients with knee osteoarthritis and rheumatoid arthritis following arthroplasty.

\section{Methods}

\section{Study design and patients}

A retrospective case-control study was conducted to analyze the effect of three different drainage techniques on reducing bone loss following TKA. Approval for this investigation was obtained from the ethics committee of our institution (Second Affiliated Hospital, School of Medicine, Zhejiang University). A written informed consent was obtained from all the patients when they were admitted, in which the patients understood and confirmed that the clinical data could be used for scientific research but did not relate to patient's privacy. All included patients were diagnosed as osteoarthritis or rheumatic arthritis and treated with unilateral TKA from January 2014 to July 2017. The patients were excluded if they had pre-operative deep vein thrombosis (DVT), poorly controlled hypertension, severe diabetes mellitus, severe anemia, coagulation dysfunction, bilateral TKA, or revision TKA. DVT was diagnosed by ultrasound, and controlled hypertension was defined as a systolic BP $<140 \mathrm{mmHg}$ and a diastolic BP $<90 \mathrm{mmHg}$.

A total of 231 patients were included and divided into three groups with different drainage methods after TKA. The groups were designed as follows: 76 patients underwent 12-hour natural drainage in Group A, 80 patients underwent 4-hour clamping drainage in Group B, and 75 patients underwent continuous drainage in Group C.

\section{Surgical and drainage techniques}

All operations were performed by senior surgeons, who were experienced in TKAs, and the same surgical technique was used for all patients. Tourniquet was used in all operations and the time of tourniquet inflation was recorded. All patients received $1 \mathrm{~g}$ tranexamic acid intravenously and $1 \mathrm{~g}$ tranexamic acid intra-articularly. The drainage tube was inserted into aponeurotic fascia before the wound was closed. All of drainage bottles were Drainobag ${ }^{\circledR} 600$ (B. Braun Medical Inc., Melsungen, Germany). In Group A, 12-hour natural drainage was used in the first 12 hours after TKA, of which the drainage pressure equaled to atmospheric pressure. Then negative pressure drainage was used after 12 hours by pumping $500 \mathrm{~mL}$ air out of the drainage bottle. In Group $\mathrm{B}$, the drainage tube was clamped for 4 hours after TKA. Then the clamp was released after 4 hours. In Group C, continuous negative pressure drainage was used immediately after TKA. All the drainage tubes were taken away at 24-36 hours after surgery. All patients received the same dose of low molecular heparin in the first post-operative 48 hours. The patients received similar exercises of continuous passive motion after surgery.

The surgical wound was assessed for any complications by surgeons every 2 days. The patient required blood transfusion when the level of serum hemoglobin (serum $\mathrm{Hb}$ ) was $<6 \mathrm{~g} / \mathrm{dL}$ or $<8 \mathrm{~g} / \mathrm{dL}$ with symptomatic anemia (such as lower systolic pressure, tachycardia, or decreasing urine output).

\section{Outcomes}

The data of pre-operation, intra-operation, and post-operation were selected for statistical analysis. The characteristics included sex, age, body mass index (BMI), time of tourniquet, baseline values of serum $\mathrm{Hb}$ and hematocrit (Hct), operation time, blood volume (BV), and intra-operative blood loss. Blood volume was calculated by the following formula: $\mathrm{BV}=\mathrm{k}_{1}{ }^{*} \mathrm{H}^{3}+\mathrm{k}_{2}{ }^{*} \mathrm{~W}+\mathrm{K}_{3} \cdot{ }^{17}$ Here $\mathrm{k}_{1}=0.3669, \mathrm{k}_{2}=0.03219$, and $\mathrm{k}_{3}=0.1833$ for male and $\mathrm{k}_{1}=0.6041, \mathrm{k}_{2}=0.03308$, and $\mathrm{k}_{3}=0.1833$ for female. BV was blood volume and its measurement unit was liter. $\mathrm{H}$ was the height of patient and its measurement unit was meter. $\mathrm{W}$ was the weight of patient and its measurement unit was kilogram. The intra-operative blood loss was calculated by the volume of surgical suction and the increased weight of gauze.

The primary outcome measurement was the total blood loss (TBL), which was assessed by post-operative drainage volume, serum $\mathrm{Hb}$, and subsequent transfusion requirements. 
Nursing team recorded the post-operative volume of surgical drainage every day. Serum $\mathrm{Hb}$ at baseline, 1, and 3 days were recorded as $\mathrm{Hb}_{0}, \mathrm{Hb}_{1}$, and $\mathrm{Hb}_{3}$, respectively, and serum Hct at baseline, 1 , and 3 days were recorded as Hct $_{0}$, $\mathrm{Hct}_{1}$, and $\mathrm{Hct}_{3}$, respectively. We recorded $\mathrm{Hb}$ from transfusion as $\mathrm{Hb}_{\mathrm{t}}$. TBL was calculated by the following formula: $\mathrm{TBL}=\mathrm{BV}^{*}\left(\mathrm{Hct}_{0}-\mathrm{Hct}_{\mathrm{n}}\right)+\mathrm{V}_{\mathrm{t}}{ }^{18}$ Here TBL was total blood loss, BV was blood volume, Hct $_{n}$ was serum Hct at $\mathrm{n}$ days after TKA, and $\mathrm{V}_{\mathrm{t}}$ was the volume of transfusion blood. TBL, BV, and $\mathrm{V}_{\mathrm{t}}$ had the same measurement unit.

Secondary outcomes included range of passive and active motion at 1 and 3 days, number of blood transfusion cases, inpatient duration, and post-operative complications.

\section{Statistical analysis}

All statistical analyses were performed on GraphPad Prism 7 (GraphPad Software Inc., San Diego, CA, USA). Number and calculated frequencies were used for chi-squared test for qualitative variables. Student's $t$-test was used to determine the difference in mean in drainage volume, blood loss, serum $\mathrm{Hb}$, range of motion (ROM), etc. The level of $P<0.05$ was considered as significant.

\section{Results}

\section{Characteristics and pre-operative baseline data of patients}

All of the characteristics of patients, baseline values, and detailed operative data are presented in Table 1. No significant difference was observed in sex, age, BMI, time of tourniquet, $\mathrm{Hb}_{0}, \mathrm{Hct}_{0}, \mathrm{BV}$, and operation time among these three groups. The intra-operative blood loss was $132.21 \pm 28.98$ $\mathrm{mL}$ in Group A, 127.32 $\pm 21.77 \mathrm{~mL}$ in Group B, and
135.21 $\pm 25.56 \mathrm{~mL}$ in Group C. There was no significant difference between every two groups.

\section{Post-operative drainage volume and serum $\mathrm{Hb}$}

The post-operative volume of drainage is illustrated in Figure 1. Group A had significantly less volume of postoperative drainage than Group B or $\mathrm{C}$ at $0-6$ hours and 6-12 hours after TKA $(P<0.05)$. No difference was found at post-operative 12-24 hours. At the end of drainage, Group A had significantly less total volume of post-operative drainage than Group B or C $(P<0.05)$. The post-operative serum $\mathrm{Hb}$ is illustrated in Figure 2. Group A had significantly higher serum $\mathrm{Hb}$ level than Group $\mathrm{B}$ or $\mathrm{C}$ at 1 and 3 days after TKA $(P<0.05)$.

\section{Post-operative blood loss}

The post-operative blood loss was calculated using the Mercuriali formula ${ }^{17}$ and is illustrated in Figure 3. At 1 and 3 days after TKA, Group A had significantly lower TBL than Group B or C $(P<0.05)$.

\section{Range of motion of knee}

Exercises of continuous passive motion were conducted since the second day after TKA, and the range of passive and active motion was recorded at 2-5 days after TKA. There was no significant difference in the maximum of passive motion of the knee among the three groups at 2-5 days after TKA (Table 2). The maximum of active motion of the knee was greater in Group $\mathrm{C}$ than those in Groups $\mathrm{A}$ and $\mathrm{B}$ at 2 days after TKA $(P<0.05)$. No significant difference was found in the maximum of active motion of the knee among the three groups at 3-5 days after TKA.

Table I The characteristics, baseline, and detailed operative data of patients

\begin{tabular}{|c|c|c|c|c|c|c|}
\hline \multirow[t]{2}{*}{ Parameters } & \multirow{2}{*}{$\begin{array}{l}\text { Group A, } \\
\text { mean } \pm \text { SD }\end{array}$} & \multirow{2}{*}{$\begin{array}{l}\text { Group B, } \\
\text { mean } \pm \text { SD }\end{array}$} & \multirow{2}{*}{$\begin{array}{l}\text { Group C, } \\
\text { mean } \pm \text { SD }\end{array}$} & \multicolumn{3}{|c|}{ P-value } \\
\hline & & & & $\mathbf{P I}$ & P2 & P3 \\
\hline Sex (male/female) & $28 / 48$ & $31 / 49$ & $24 / 51$ & 0.81 & 0.53 & 0.38 \\
\hline Age (years) & $66.89 \pm 7.69$ & $67.35 \pm 8.44$ & $67.01 \pm 8.91$ & 0.36 & 0.51 & 0.62 \\
\hline BMI $\left(\mathrm{kg} / \mathrm{m}^{2}\right)$ & $25.89 \pm 4.58$ & $26.38 \pm 5.56$ & $25.44 \pm 5.12$ & 0.11 & 0.28 & 0.61 \\
\hline Time of tourniquet (min) & $65.20 \pm 18.58$ & $68.35 \pm 22.47$ & $66.84 \pm|7.8|$ & 0.41 & 0.38 & 0.55 \\
\hline $\mathrm{Hb}_{0}(\mathrm{~g} / \mathrm{L})$ & $129.35 \pm 13.8$ & $|27.84 \pm| 5.4 \mid$ & $130.73 \pm 14.99$ & 0.24 & 0.33 & 0.52 \\
\hline $\mathrm{Hct}_{0}(\mathrm{~L} / \mathrm{L})$ & $0.37 \pm 0.05$ & $0.39 \pm 0.07$ & $0.36 \pm 0.07$ & 0.88 & 0.79 & 0.66 \\
\hline $\mathrm{BV}(\mathrm{L})$ & $4.01 \pm 0.67$ & $3.97 \pm 0.71$ & $4.04 \pm 0.77$ & 0.48 & 0.65 & 0.71 \\
\hline Operation time (min) & $75.98 \pm \mid 7.21$ & $72.12 \pm 14.32$ & $78.14 \pm 15.69$ & 0.49 & 0.31 & 0.12 \\
\hline Intraoperative blood loss (mL) & $|32.2| \pm 28.98$ & $127.32 \pm 21.77$ & $|35.2| \pm 25.56$ & 0.35 & 0.68 & 0.10 \\
\hline
\end{tabular}

Notes: Group A, I2-hour natural drainage ( $n=76)$; Group B, 4-hour clamping drainage $(n=80)$; Group C, continuous drainage ( $n=75)$. PI: $P$-value of significance between Groups A and B; P2: P-value of significance between Group A and C; P3: P-value of significance between Group B and C.

Abbreviations: $\mathrm{BMI}$, body mass index; $\mathrm{Hb}_{0}$, preoperative serum hemoglobin; $\mathrm{Hct}_{0}$, preoperative serum hematocrit; $\mathrm{BV}$, blood volume. 


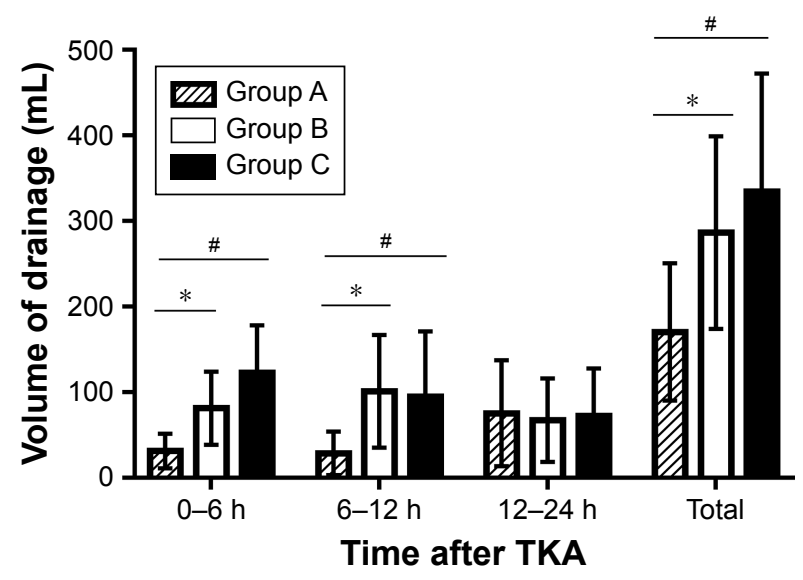

Figure I The mean post-operative drainage volume in three groups.

Notes: Group A, 12-hour natural drainage $(n=76)$; Group B, 4-hour clamping drainage $(n=80)$; Group C, continuous drainage $(n=75)$. Group A had significantly lower drainage volume than Groups $B$ and $C$ at $0-6$ hours and 6-12 hours after TKA $(P<0.05)$. No difference was found at post-operative I2-24 hours. At the end of drainage, Group A had significantly lower total volume of drainage than Group B and Group $C$ (* and *: $P<0.05)$.

Abbreviation: TKA, total knee arthroplasty.

\section{Blood transfusion, inpatient duration, and complications}

The number of blood transfusion cases were significantly fewer in Groups A and B than that in Group C (7 cases) $(P<0.05)$ (Table 3). No significant difference was found in the number of blood transfusion cases between Group A and Group B. No significant difference was found in the inpatient duration among the three groups. There were three complications (4.0\%) in Group A, 8 (10.0\%) in Group B, and $4(5.3 \%)$ in Group C. There were 10 cases of wound blister, 4 cases of DVT, and 1 case of superficial infection. There was no significant difference in complications among the three groups.

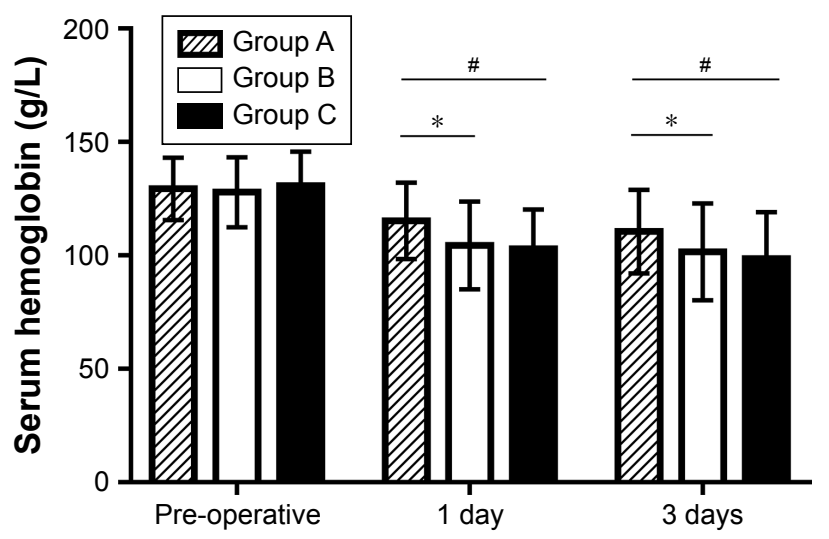

Figure 2 The mean post-operative serum hemoglobin in three groups.

Note: Group A, 12-hour natural drainage $(n=76)$; Group B, 4-hour clamping drainage $(n=80)$; Group C, continuous drainage $(n=75)$. Group A had significantly higher serum hemoglobin level than Groups $B$ and $C$ at $I$ and 3 days after TKA (* and $\left.{ }^{*}: P<0.05\right)$.

Abbreviation: TKA, total knee arthroplasty.

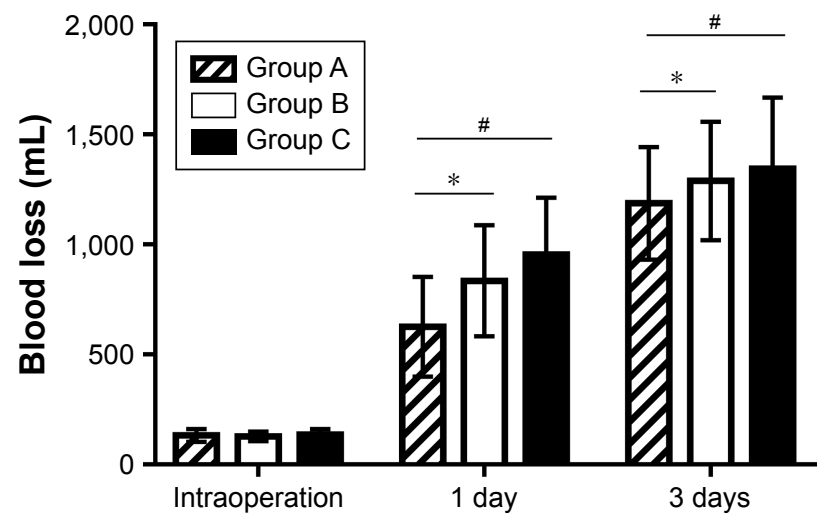

Figure 3 The mean post-operative blood loss in three groups.

Note: Group A, 12-hour natural drainage $(n=76)$; Group B, 4-hour clamping drainage $(n=80)$; Group C, continuous drainage $(n=75)$. The post-operative blood loss was calculated using the Mercuriali formula and Group A had significantly lower total blood loss than Groups B and $C$ at $I$ and 3 days after TKA (* and $\#$ : $P<0.05$ ). Abbreviation: TKA, total knee arthroplasty.

\section{Discussion}

The present study is the first investigation of a novel postoperative natural drainage after TKA. In comparison with 4-hour clamping drainage and continuously negative drainage, 12-hour natural drainage can decrease the blood loss and number of blood transfusion cases after TKA but does not increase complications. The main result of this study confirms that the 12-hour natural drainage is an effective drainage strategy after TKA.

The post-operative anemia is an important problem in patients with TKA. Several approaches have been investigated to decrease blood loss after TKA. The clamping drainage, which is believed to have a tamponade effect and control the post-operative blood loss, is routinely used. ${ }^{19}$ Prior studies have examined many clamping methods, such as the intermittent method and the specific hour-drain clamping after arthroplasty, and have determined that 3-6 hours of clamping has the best effect. ${ }^{16}$ However, it is also reported that temporary clamping of drain may increase hematoma formation, which may increase post-operative pain, swelling, and risk of infection. ${ }^{12}$ A technique of temporary natural drainage has been used and could reduce blood loss after total thyroidectomy compared with continuous negative drainage. ${ }^{20}$ Our results support the application of temporary natural drainage to reduce blood loss after TKA. Moreover, the TBL in this study was obviously less than other previous studies. ${ }^{21-23}$ The first possible interpretation is that all the TKAs are conducted by senior surgeons according to strict standards. Secondly, tranexamic acid is used in all the patients, which has been proved to be able to reduce the blood loss. 
Table 2 The operative range of motion

\begin{tabular}{|c|c|c|c|c|c|c|}
\hline \multirow[t]{2}{*}{ Parameters } & \multirow{2}{*}{$\begin{array}{l}\text { Group A, } \\
\text { mean } \pm \text { SD }\end{array}$} & \multirow{2}{*}{$\begin{array}{l}\text { Group B, } \\
\text { mean } \pm \text { SD }\end{array}$} & \multirow{2}{*}{$\begin{array}{l}\text { Group C, } \\
\text { mean } \pm \text { SD }\end{array}$} & \multicolumn{3}{|c|}{$P$-value } \\
\hline & & & & $\overline{P I}$ & $\mathbf{P 2}$ & P3 \\
\hline \multicolumn{7}{|c|}{ Maximum of passive motion } \\
\hline Day 2 & $62.54 \pm 17.62$ & $61.14 \pm 18.32$ & $63.14 \pm 15.58$ & 0.812 & 0.095 & 0.146 \\
\hline Day 3 & $82.65 \pm 20.5 \mid$ & $80.17 \pm 19.19$ & $81.27 \pm 19.18$ & 0.546 & 0.187 & 0.442 \\
\hline Day 4 & $97.08 \pm 22.65$ & $96.38 \pm 24.56$ & $99.33 \pm 25.12$ & 0.264 & 0.234 & $0.48 I$ \\
\hline Day 5 & $98.55 \pm 23.88$ & $|02.33 \pm 24.4|$ & $100.69 \pm 20.78$ & 0.106 & 0.187 & 0.421 \\
\hline \multicolumn{7}{|c|}{ Maximum of active motion } \\
\hline Day 2 & $28.62 \pm 14.33$ & $27.45 \pm 20.21$ & $38.32 \pm 18.55$ & 0.765 & $0.04 I$ & 0.038 \\
\hline Day 3 & $42.43 \pm 22.49$ & $40.7 I \pm 19.85$ & $41.63 \pm 18.72$ & 0.214 & 0.122 & 0.343 \\
\hline Day 4 & $51.68 \pm 17.65$ & $48.30 \pm 23.13$ & $51.11 \pm 24.10$ & 0.312 & 0.415 & 0.106 \\
\hline Day 5 & $63.27 \pm 26.88$ & $54.33 \pm 24.41$ & $65.14 \pm 22.86$ & 0.087 & 0.174 & 0.092 \\
\hline
\end{tabular}

Notes: Group A, I2-hour natural drainage ( $n=76)$; Group B, 4-hour clamping drainage $(n=80)$; Group C, continuous drainage ( $n=75)$. PI: $P$-value of significance between Groups A and B; P2: P-value of significance between Group A and C; P3: P-value of significance between Group B and C.

The results of our study show that the drainage volume is reduced by $\sim 30 \%-50 \%$ in the temporary natural drainage group compared with temporary clamping or continuous negative pressure drainage group. It is reported that the maximum loss of blood occurs in 4-12 hours after TKA. ${ }^{24}$ There is $75 \%$ of TBL occurring at the first 12 hours following TKA..$^{25}$ The control of blood loss has the most effect during this period. The volume of blood loss is indirectly calculated by serum Hct, but a lower transfusion rate directly revealed that temporary natural drainage and temporary clamping drainage could maintain less blood loss than continuous negative pressure drainage.

The active motion was a little better in continuous negative pressure drainage group than that in temporary natural drainage group and temporary clamping drainage group. A possible interpretation is that the temporary natural drainage or temporary clamping drainage leads to local swelling and limitation of motion.

Table 3 Blood transfusion, inpatient duration, and complications

\begin{tabular}{|c|c|c|c|c|c|c|}
\hline \multirow[t]{2}{*}{ Parameters } & \multirow[t]{2}{*}{ Group A } & \multirow[t]{2}{*}{ Group B } & \multirow[t]{2}{*}{ Group C } & \multicolumn{3}{|c|}{$P$-value } \\
\hline & & & & $\mathbf{P I}$ & P2 & P3 \\
\hline Blood transfusion & 3 & 4 & 12 & 0.751 & 0.013 & 0.034 \\
\hline Inpatient duration & 7.42 & 7.64 & 7.55 & 0.410 & 0.221 & 0.348 \\
\hline $\begin{array}{l}\text { Skin tension } \\
\text { blister }\end{array}$ & 2 & 5 & 3 & 0.792 & 0.712 & 0.527 \\
\hline DVT & I & 2 & 1 & 0.590 & 0.993 & 0.598 \\
\hline $\begin{array}{l}\text { Superficial } \\
\text { infection }\end{array}$ & 0 & 1 & 0 & 0.328 & 1.000 & 0.971 \\
\hline $\begin{array}{l}\text { Total } \\
\text { complications }\end{array}$ & 3 & 8 & 4 & 0.140 & 0.686 & 0.277 \\
\hline
\end{tabular}

Notes: Group A, 12-hour natural drainage ( $n=76)$; Group B, 4-hour clamping drainage $(n=80)$; Group C, continuous drainage $(n=75)$. PI: $P$-value of significance between Groups A and B; P2: P-value of significance between Group A and C; P3: $P$-value of significance between Group $B$ and $C$.

Abbreviation: DVT, deep vein thrombosis.
Although no difference has been found in complications among the three groups, a few more wound blisters have been found in patients with temporary clamping drainage. A possible interpretation is that the clamping drainage induced temporary hematoma accumulation, which increases local skin tension. The thresholds for transfusion in the present study are significantly lower than those in other countries. There are more patients but relatively less blood resource in People's Republic of China. There was no patient who had clot in the tubing and the reason may be the good design of drain system.

Conventionally, the drainage should be removed when the drainage volume is $<20-30 \mathrm{~mL}$ per day. Therefore, drainage volume is an important factor that determines inpatient duration. Thus, temporary natural drainage not only decreases perioperative blood loss, but it also decreases the medical cost to patients.

There are several limitations of this study. Firstly, this retrospective case-control study is limited in scope to preliminarily test the hypothesis. Future prospective randomized controlled trials are necessary to confirm these findings. Secondly, although the sample size is not small compared with previous studies, it is insufficient to analyze the clinical complications. Thirdly, the ranges of ROM are so large as to preclude useful clinical application, although there was significance. Fourthly, it should be better if the present study had an additional comparison group of those closed with no drainage.

\section{Conclusion}

The 12-hour natural drainage is an effective technique for reducing blood loss in patients following TKA. Compared with temporary clamping drainage or continuous negative pressure drainage, 12-hour natural drainage decreases blood loss, reduces post-operative transfusion requirements, and does not increase risk of complications. In conclusion, the 
novel technique of 12-hour natural drainage is recommended to be used in patients undergoing TKA.

\section{Acknowledgments}

This research was supported by National Natural Science Foundation of China under Grant No. 81772360, Zhejiang Province Natural Science Foundation of China under Grant No. LQ16H060002, Zhejiang Province Natural Science Foundation of China under Grant No. Y17H060027, Medical and Health Science and Technology Project of Zhejiang Province under Grant No. 2016KYB120, Health Foundation of Zhejiang Province under Grant No.2018263059, and China Postdoctoral Science Foundation under Grant No. 2017M612012.

\section{Disclosure}

The authors report no conflicts of interest in this work.

\section{References}

1. Lovelock TM, Broughton NS. Follow-up after arthroplasty of the hip and knee: are we over-servicing or under-caring? Bone Joint J. 2018; 100-B(1):6-10.

2. Ritter MA, Keating EM, Faris PM. Closed wound drainage in total hip or total knee replacement. A prospective, randomized study. J Bone Joint Surg Am. 1994;76(1):35-38.

3. Park JH, Rasouli MR, Mortazavi SM, Tokarski AT, Maltenfort MG, Parvizi J. Predictors of perioperative blood loss in total joint arthroplasty. J Bone Joint Surg Am. 2013;95(19):1777-1783.

4. Charoencholvanich K, Siriwattanasakul P. Tranexamic acid reduces blood loss and blood transfusion after TKA: a prospective randomized controlled trial. Clin Orthop Relat Res. 2011;469(10):2874-2880.

5. Aksoy Y, Altinel L, Köse KÇ. The comparison of the effects of intraoperative bleeding control and postoperative drain clamping methods on the postoperative blood loss and the need for transfusion following total knee arthroplasty. Acta Orthop Traumatol Turc. 2011;45(3):190-194.

6. Gao F, Ma J, Sun W, Guo W, Li Z, Wang W. Topical fibrin sealant versus intravenous tranexamic acid for reducing blood loss following total knee arthroplasty: a systematic review and meta-analysis. Int J Surg. 2016;32:31-37.

7. Stucinskas J, Tarasevicius S, Cebatorius A, Robertsson O, Smailys A, Wingstrand $\mathrm{H}$. Conventional drainage versus four hour clamping drainage after total knee arthroplasty in severe osteoarthritis: a prospective, randomised trial. Int Orthop. 2009;33(5):1275-1278.

8. Banerjee S, Kapadia BH, Issa K, et al. Postoperative blood loss prevention in total knee arthroplasty. J Knee Surg. 2013;26(6):395-400.

9. Kim YH, Cho SH, Kim RS. Drainage versus nondrainage in simultaneous bilateral total knee arthroplasties. Clin Orthop Relat Res. 1998; (347):188-193
10. Esler CN, Blakeway C, Fiddian NJ. The use of a closed-suction drain in total knee arthroplasty. A prospective, randomised study. $J$ Bone Joint Surg Br. 2003;85(2):215-217.

11. Zhou K, Wang H, Li J, Wang D, Zhou Z, Pei F. Non-drainage versus drainage in tourniquet-free knee arthroplasty: a prospective trial. $A N Z$ J Surg. 2017;87(12):1048-1052.

12. Wu Y, Yang T, Zeng Y, Li C, Shen B, Pei F. Clamping drainage is unnecessary after minimally invasive total knee arthroplasty in patients with tranexamic acid: a randomized, controlled trial. Medicine (Baltimore). 2017;96(7):e5804.

13. Pornrattanamaneewong C, Narkbunnam R, Siriwattanasakul P, Chareancholvanich $\mathrm{K}$. Three-hour interval drain clamping reduces postoperative bleeding in total knee arthroplasty: a prospective randomized controlled trial. Arch Orthop Trauma Surg. 2012;132(7):1059-1063.

14. Kiely N, Hockings M, Gambhir A. Does temporary clamping of drains following knee arthroplasty reduce blood loss? A randomised controlled trial. Knee. 2001;8(4):325-327.

15. Tai TW, Yang CY, Jou IM, Lai KA, Chen CH. Temporary drainage clamping after total knee arthroplasty: a meta-analysis of randomized controlled trials. J Arthroplasty. 2010;25(8):1240-1245.

16. Jeon YS, Park JS, Kim MK. Optimal release timing of temporary drain clamping after total knee arthroplasty. J Orthop Surg Res. 2017; 12(1):47.

17. Nadler SB, Hidalgo JH, Bloch T. Prediction of blood volume in normal human adults. Surgery. 1962;51(2):224-232.

18. Mercuriali F, Inghilleri G. Proposal of an algorithm to help the choice of the best transfusion strategy. Curr Med Res Opin. 1996;13(8): 465-478.

19. Kang Y, Zhang ZJ, Fu M, Xu DL, Sheng PY, Liao WM. Blood transfusion and drainage catheter clamping are associated with ecchymosis formation at the surgical site after total knee arthroplasty: an analysis of 102 unilateral cases. Eur J Orthop Surg Traumatol. 2013;23(2): 219-224.

20. Woo SH, Kim JP, Park JJ, et al. Comparison of natural drainage group and negative drainage groups after total thyroidectomy: prospective randomized controlled study. Yonsei Med J. 2013;54(1):204-208.

21. Yildiz C, Koca K, Kocak N, Tunay S, Basbozkurt M. Late tourniquet release and drain clamping reduces postoperative blood loss in total knee arthroplasty. HSS J. 2014;10(1):2-5.

22. Ryu J, Sakamoto A, Honda T, Saito S. The postoperative drainclamping method for hemostasis in total knee arthroplasty. Reducing postoperative bleeding in total knee arthroplasty. Bull Hosp Jt Dis. 1997;56(4):251-254.

23. Chareancholvanich K, Siriwattanasakul P, Narkbunnam R, Pornrattanamaneewong $\mathrm{C}$. Temporary clamping of drain combined with tranexamic acid reduce blood loss after total knee arthroplasty: a prospective randomized controlled trial. BMC Musculoskelet Disord. 2012;13:124.

24. Senthil Kumar G, Von Arx OA, Pozo JL. Rate of blood loss over 48 hours following total knee replacement. Knee. 2005;12(4):307-309.

25. Jou IM, Lai KA, Yang CY, Lin RM, Lin CJ, Liu J. Blood loss associated with total knee arthroplasty. J Orthop Surg. 1993;10(2):213-218.
Therapeutics and Clinical Risk Management

\section{Publish your work in this journal}

Therapeutics and Clinical Risk Management is an international, peerreviewed journal of clinical therapeutics and risk management, focusing on concise rapid reporting of clinical studies in all therapeutic areas, outcomes, safety, and programs for the effective, safe, and sustained use of medicines. This journal is indexed on PubMed Central, CAS,

\section{Dovepress}

EMBase, Scopus and the Elsevier Bibliographic databases. The manuscript management system is completely online and includes a very quick and fair peer-review system, which is all easy to use. Visit $\mathrm{http}: / / \mathrm{www}$.dovepress.com/testimonials.php to read real quotes from published authors. 